\title{
ARSYAD MADDAPUNGAN: PUANG PANRITA PENCETAK PARA PANRITA
}

\author{
Arsyad Maddapungan: \\ A Scholar Generated the Scholars
}

\author{
Syarifuddin \\ Balai Penelitian dan Pengembangan Agama Makassar \\ Jl. A.P. Pettarani No. 72 Makassar \\ Email: syarifuddinamir84@yahoo.com
}

Naskah diterima tanggal 4 Februari 2014. Naskah direvisi tanggal 6 Mei 2014. Naskah disetujui tanggal 12 Mei 2014

\begin{abstract}
Abstrak
Penelitian ini membahas tentang biografi Arsyad Maddappungan sebagai ulama yang mengembangkan tradisi mangngaji kitta' di Campalagian Polman dengan metode mangngolo atau sorogan. Dalam tradisi NU, penguasaan kitab kuning merupakan syarat utama keulamaan seseorang. Lewat mangngaji kitta' (pengajian kitab kuning), Arsyad Maddapungan ulama dari Belokka Sidrap mengkader ulama-ulama yang berasal dari berbagai daerah di Sulawesi Barat. Selanjutnya, mereka inilah melanjutkan tradisi mangangji kitta' tersebut. Tradisi mangngaji kitta' hingga kini masih lestari di Campalagian. Sistem pembelajaran ini terbukti menghasilkan qari-qari kutub turast yang mampu menguasai qaidahqaidah Bahasa Arab dan memahami isi kitab kuning. Salah satu ciri khas pengajian ini yaitu dimulai dengan penguasaan kaidah saraf dengan menggunakan saraf galappo dilanjutkan dengan penguasaan kaidah-kaidah nahwu. Penguasaan kedua cabang ilmu bahasa Arab ini menjadi prioritas utama dalam pembelajaran kitab kuning karena merupakan dasar utama bagi santri dalam menguasai dan memahami kitab kuning.
\end{abstract}

Kata kunci: mangngaji kitta', kitab kuning, saraf galappo

\begin{abstract}
The research accounts the biography of Arsyad Maddapungan as Islamic scholar who developed the tradition of reciting the Koran in Campalagian Polman by employing mangngolo or sorogan method. Based on the Nahdatul Ulama tradition, the mastery of islamic book with arabic script (kitab kuning) is the major requirement to be an Islamic scholar. Through reciting the Koran, Arsyad Maddapungan as the Islamic scholar from Belokka, Sidrap educated the other Islamic scholars from different areas in west Sulawesi. They then continued the tradition of reciting the Koran. As the result, the tradition of reciting the Koran still sustains in Campalagian. This learning system prove to generate the great reciters who were able to master the rules of Arabic language and to understand the contents of yellow book. One of the distinctive features of this teaching was started from the mastery of the saraf rules by using saraf galappo then followed by mastering the nahwu rules. The mastery of both Arabic language branches became the top priority in the islamic book with arabic script (kitab kuning) learning as a primary basis for students in mastering and understanding the islamic book with arabic script (kitab kuning).
\end{abstract}

Keywords: reciting the koran, islamic book with arabic script (kitab kuning), Saraf Galappo

\section{PENDAHULUAN}

$\mathrm{S}$ ejak awal abad 20 pendidikan Islam di Sulawesi Selatan mengalami perkembangan pesat. Umumnya perkembangan ini dipelopori oleh para ulama yang oleh masyarakat lebih dikenal dengan sebutan Anrongguru. Terdapat beberapa daerah yang menjadi pusat pendidikan Islam, misalnya di Sengkang Wajo yang dirintis oleh Kiai Muhammad As'ad atau lebih dikenal dengan sebutan dengan Gurutta Sade'. Ia mendirikan sebuah lembaga yaitu Madrasah Arabiyah al-Islamiyah 
(MAI) yang biasanya oleh masyarakat setempat disebut Sekolah Arab. Berbekal dengan ilmu dan pengalaman selama menuntut ilmu di Mekah, Gurutta Sade membangun perguruan tersebut hingga menjadikan Sengkang pada waktu sebagai pusat Pendidikan di Sulawesi Selatan. Gurutta Sade' kemudian berhasil mengkader beberapa kader ulama yang kelak menjadi pionir perkembangan pendidikan Islam selanjutnya.

Gurutta Sade' menjadi satu-satunya pengajar pada perguruan Islam tersebut hingga kemudian ia dibantu oleh murid-muridnya yang telah diangap cakap antara lain; Abdulrahman Ambo Dalle dari Barru, Daud Ismail dari Soppeng, Yunus Maratan dari Belawa Wajo serta Abdul Rauf dari Palopo. Perguruan Islam kini dikenal dengan Pesantren As'adiyah mengambil nama dari Muhammad As'ad (Pawiloy, 1981: 81-82).

Selanjutnya usaha pengembangan pendidikan Islam juga terjadi di daerah lain seperti Barru. Dalam hal ini Abdur Rahman Ambo Dalle sepulang dari Sengkang menuntut ilmu pada Muhammad As'ad. Ia kemudian merintis lembaga yang sama dengan yang dirintis oleh Gurutta Sade' yaitu Madrasah Arabiyah al-Islamiyah (MAI) yang berpusat di Mangkoso Barru. Walaupun sebenarnya lembaga ini tidak memiliki keterikatan organisasi. Lembaga ini didirikan juga berkat fasilitas dari Arung Kerajaan Soppeng Riaja.

Gurutta Ambo Dalle awalnya mengadakan pengajian di masjid Mangkoso. Hingga kemudian berkembang setelah jumlah santri semakin bertambah. Ia membagi pada beberapa tingkatan sesuai dengan kemampuan santri. Selanjutnya MAI Mangkoso semakin berkembang hingga dibuka tingkatan tahdiriyah, ibtidaiyah dan tsanawiyah. Ambo Dalle kemudian dibantu oleh santri-santri seniornya seperti: Muhammad Amberi Said, Muhammad Amin Natsir, Haruna Rasyid, Abd. Rahman Mattameng, Hannan, Akib Siangka, Abd. Rasyid, Muhammadiyah, Burhanuddin dan Muhammad Makki. Sebagian besar dari yang membantu Ambo Dalle merupakan santri dari Sengkang kecuali Burhanuddin dari Salemo dan Muhammadiyah dari Campalagian dan Salemo. (Bosra, 2008:169-170).

Sementara itu jauh sebelumnya, di Campalagian sudah dikenal pengajian kitab kuning dengan sistem tradisional yang dikenal dengan metode sorogan yaitu tiap santri membacakan masing-masing kitab yang dipelajari kemudian guru menerjemahkan, menjelaskan dan memperbaiki kesalahan bacaan dari santri. Sistem pengajian ini diinisiasi oleh ulama setempat.

Sistem pengajian kitab (mangngaji kitta') mencapai puncak keemasannya pada masa Arsyad Maddappungan seorang ulama berasal dari Belokka Sidrap. Tidak diketahui secara pasti kapan dan siapa yang memulai mengadakan pengajian kitab di Campalagian. Hanya saja sebelum Arsyad Maddappungan, Qadhi Abdul Hamid (mertua Maddappungan) dan Syekh Abdul Karim (pamam Maddappungan) telah mengadakan pengajian kitab.

Sepeninggal Arsyad Maddappungan, usaha itu kemudian dilanjutkan oleh santri sekaligus menantunya Muh. Zein yang menggantikan posisinya sebagai Qadhi Campalagian. Lalu, diteruskan oleh Hudaedah murid Muh. Zein hingga kini (Muslim, 2012). Hingga kini tradisi pengajian kitab dengan sistem tradisional masih berlangsung di Campalagian. Namun, di samping berlangsung di rumah guru-guru, pengajian kitab dengan sistem tersebut sudah terintegrasi dalam sistem pesantren yang didirikan oleh Abd. Latif santri dari Muh. Zein dengan nama Pesantren Salafiyah Campalagian. Metode ini cukup terbukti menghasilkan qari-qari kutub turats (kitab kuning) yang mumpuni.

Realitas tersebut menjadi menarik untuk diteliti terlebih membaca karya biografi ulamaulama dari Mandar, lebih didominasi oleh ulama tariqat seperti Muh. Saleh yang mengembangkan Tarekat Qadiriyah, Abdurrahman Qadir dengan tarekat Naqsyabandiyah serta Muh. Tahir yang yang lebih dikenal dengan sebutan Imam Lapeo membawa Tarekat Syadziliyah. Sementara kajian ulama-ulama yang berbasis kitab kuning masih sangat minim.

Berdasarkan latar belakang yang telah dikemukakan, pertanyaan penelitian yang diangkat sebagai masalah penelitian ini, yaitu: Bagaimana biografi Arsyad Maddappungan di Polman Sulawesi Barat? Pertanyaan ini dijabarkan dalam sub permasalahan sebagai berikut: Bagaimana perkembangan tradisi mangngaji kitta' di Polman? Bagaimana kehidupan pribadi Arsyad Maddappungan? serta bagaimana dakwah Arsyad Maddappungan?

Teori yang digunakan dalam tulisan ini yaitu teori tentang Ulama. Kata ulama berasal dari bahasa Arab yang merupakan bentuk jamak dari kata alim yang berarti berilmu (terutama dalam hal agama Islam). Kata ulama dipakai sebagai kata 
tunggal yang bermakna orang yang ahli dalam hal atau dalam pengetahuan Islam. Awalnya, tidak ada pembatasan ilmu secara spesifik dalam pengertian ini. Tetapi dengan berkembangnya ilmu-ilmu Islam, khususnya syariat dan fikih. Akhirnya pengertian ulama menyempit menjadi orang yang memiliki pengetahuan mendalam dalam ilmu fikih. (Azra, 2009: xxviii).

Dalam Islam, ulama diposisikan sebagai pewaris Nabi Muhammad saw dalam mengembangkan ajaran Islam. Khusus di masyarakat Mandar, ulama dikenal dengan sebutan annangguru, meskipun kadang juga disebut kiai (sebutan ulama pada masyarakat Jawa). Di Mandar, sebutan annangguru bukan saja disematkan pada ulama, tetapi sebutan annangguru juga diberikan kepada orang yang mempunyai profesi khsusus seperti annangguru lopi (orang yang ahli membuat perahu, annangguru boyang (orang yang ahli rumah kayu) dan sebagainya (Musaddad, 2008:52).

Pada tahun 2011, Balai Litbang Agama melakukan penelitian biografi ulama beserta karya tulisnya yang kemudian diterbitkan Buah Pena Sang Ulama (As'ad, 2012: 8-9), pada beberapa tempat di Kawasan Timur Indonesia yang dilanjutkan dengan penelitian Biografi ulama perempuan pada tahun 2012. Dalam penelitian ini ditetapkan bahwa teori keulamaan seseorang diukur pada empat aspek yaitu; memiliki yang luas dalam bidang agama Islam khususnya fikih, berakhlak mulia, menyebarkan ilmu yang dimiliki serta memiliki penguasaan kitab kuning.

\section{METODE PENELITIAN}

Penelitian ini merupakan penelitian kualitatif biografi yang memotret life story seorang tokoh yang diteliti. Penelitian ini dilaksanakan di Kecamatan Campalagian Kabupaten Polewali Mandar, Provinsi Sulawesi Barat sebagai lokasi Arsyad Maddappungan menjalankan perannya sebagai ulama. Teknik pengumpulan data yang dipergunakan adalah: Observasi terhadap lingkungan sekitar Arsyad Maddappungan, terutama kehidupan keagamaannya, wawancara dengan berbagai informan yang relevan, serta studi pustaka dan dokumen yang berkaitan dengan penelitian. Karena penelitian ini merupakan penelitian kualitatif maka analisis data dilakukan dengan analisis kualitatif deskriptif. Akan dilakukan kategorisasi data, mengaitkan data yang relevan dan menarasikannya.

\section{PEMBAHASAN \\ Biografi Arsyad Maddapungan}

Arsyad Maddappungan yang lebih dikenal dengan panggilan Puang Panrita dilahirkan pada tahun 1884 Masehi di Belokka Kecamatan Pancalautan Sidrap. Ia lahir dari pasangan Abdul Fattah dan Kallabbu. Nama Maddappungan sendiri merupakan nama khas bugis yang berarti berkumpul. Strata keluarga Maddappungan di masyarakat termasuk dalam golongan bangsawan dan tokoh masyarakat. Sementara tambahan nama Arsyad merupakan pemberian nama oleh gurunya. Maddappungan memiliki 2 saudara (kakak) yaitu Manrulu dan Masseuwa. Sebagai keturunan keluarga terhormat, Maddapungan dididik oleh orang tuanya serta kakaknya Manrulu. Pada masa masih usia dini, ia kemudian dibawa ke Campalagian Polmas (kini Polewali Mandar) oleh pamamnya Abd. Karim yang dikenal dengan Syekh Belokka. Di Campalagian ia ditempa dengan pendidikan tradisional.

Seperti disebutkan sebelumnya, Maddappungan belajar agama selama 2 periode yaitu Campalagian dalam kurun waktu tahun 1903-1906 kepada kakaknya sendiri Manrulu serta pamannya Abd. Karim. Di samping itu, ia juga berguru pada M. Nur, Haji Saran serta Abd. Hamid yang kemudian menjadi mertuanya. Tekadnya yang kuat untuk mempelajari ajaran Islam membuat ia memutuskan mengikuti jejak Manrulu memperdalam ajaran Islam di tanah Suci ke beberapa ulama. Ilmu-ilmu yang dipelajari berupa tauhid, fikih, tafsir, termasuk Bahasa Arab. (Muhammadiyah, 1984: 31).

Di Jazirah Arab ia belajar kepada beberapa ulama baik di Mekah maupun Madinah (Abd. Kadir R, 2007: 272), antara lain: Syekh Abd. Rauf di Mekah, Syekh Hadrawi di Mekah, Syekh Muh. Dahlan di Mekah, Syekh Gamma di Mekah, Syekh Abd. Rasyid di Mekah, Syekh Hamdana di Madinah, dan Syekh Said Al Yamani di Mekah (mufti Syafi'iyah di Mekah).

Nama terkhir tersebut di atas yaitu Syekh Said Al Yamani dikenal sebagai guru ulama-ulama Nusantara. Tercatat beberapa ulama yang berguru kepadanya (Suprapto: 2009). Antara lain: Hasyim Asy'ari (Jombang), Abdullah Faqih (Langitan), Ali Maksum (Rembang), Arsyad al-Banjari (Banjarmasin), Zaini Mun'im (Probolinggo), Anwar Musaddad (Garut), Zainuddin Abd. Majid (Ancor), Muh. As'ad (Sengkang), serta beberapa ulamaulama lainnya.

Sepulang dari tanah suci, ia kembali ke kampung halamannya Belokka. Maddapungan 
kemudian dijodohkan oleh orang tuanya dengan seorang perempuan yang bernama Sa'diyah. Peristiwa ini terjadi pada tahun 1903. Dari perkawinan itu, ia dikarunia 3 orang anak masing-masing, Puang Ado, Muhammad dan Fatimah. Ia kemudian dipercaya menjabat qadhi Sidenreng sampai ia kemudian meninggalkan kampung halamannya dan kembali menuju Campalagian. Di sinilah kemudian ia selanjutnya mengembangkan dakwah melalui pengajian kitab. Arsyad Maddapungan sendiri memiliki kelebihan dalam pemahaman agama.

Oleh karena ilmu pengetahuan yang luas serta kecerdasannya, tokoh-tokoh agama berusaha agar Maddapppungan bisa tetap tinggal di Campalagian dalam mengembangkan pengajian yang diasuh. Oleh karena itulah pada tahun 1910, ia dijodohkan dengan salah seorang putri Qadhi Campalagian (Abd. Hamid) yang bernama St. Rabiah binti Abd. Hamid. Dari perkawinan kedua ini, ia dikarunia 13 orang anak yaitu: Abdullah Maddappungan, Muhaebah Maddappungan, Abbasiyah Maddappungan, Rafi' Maddappungan, Zainuddin Maddappungan, Sapiyah Maddappungan, Aisyah Maddappungan, Muh. Da’aming Maddappungan, Hamdanah Maddappungan, Abd. Mu'in Maddappungan, Abd. Razak Maddappungan, Muh. Ali Maddappungan dan Muh. Aco Maddappungan

Pada akhirnya Maddappungan memilih Campalagian sebagai tempat mengabdi hingga ia wafat pada tahun 1954. Di samping mengembangkan pengajian Kitab di Campalagian, ia juga dipercaya sebagai Qadhi di Binuang. Maddapungan juga sempat menjadi Qadhi Campalagian selama 6 tahun (1948-1954). Setelah wafat, ia digantikan oleh menantunya Muhammad Zein sebagai sabagai Qadhi Campalagian sekaligus melanjutkan tradisi mangngaji kitta' yang dilaksanakan di rumahnya.

\section{Tradisi Mangngaji Kitta' di Campalagian Polman}

Tradisi mengaji kitab dikenal sebagi tradisi NU. Penguasaan kitab kuning pun dianggap sebagai prasyarat untuk bisa diakui sebagai ulama. Dalam hal ini pengalaman Zaifuddin Zuhri dalam sebuah forum pengajian kitab kuning. Melalui forum ini, tingkat keulamaan ditentukan dari tingkat kemampuan dalam menjelaskan setiap kalimat dari kitab yang dikaji. (Burhanuddin, 2012: 358-359). Di Masyarakat Mandar, termasuk Campalagian, tradisi ini dikenal dengan mangngaji kitta'. Orang belajar dan pandai membaca kitab kuning disebut pangngaji kitta'.
Tidak diketahui secara pasti siapa yang mulai pengajaran kitab kuning di Campalagian, namun sebelum Arsyad Maddappungan mengembangkan model pengajian ini, terlebih dahulu Abdul Karim yang dikenal Syekh Belokka hijrah ke Campalagian dari tanah asalnya Sidrap. Selanjutnya, ia diikuti Arsyad Maddappungan yang tak lain adalah kemanakannya. Selanjutnya, beliau berangkat ke Mekah untuk lebih memperdalam ilmu agamanya. Di Mekah ia berguru kepada beberapa ulama seperti Syekh Said al-Yamani (ayah kandung Syekh Hasan Yamani) mantan mufti Syafi 'i di Masjid alHaram, Syekh Bakri Syatha' penulis kitab "I'anah al-Thalibin Syarh Fath al-Mu'in" yang menjadi pegangan di beberapa pondok salaf di Indoensia.

Sekembalinya dari Mekah, beliau tinggal dan menetap di Pontianak berkeluarga di sana. Setelah itu beliau pulang ke kampung halamannya di Belokka Sidrap Sulawesi Selatan. Dalam perjalanannya, yaitu ketika masih di wilayah Makassar, beliau sempat bertemu dengan seorang pedagang dari Mandar (Campalagian), namanya Annangguru Kaiyyang (guru besar) dan Ampona Ampo Juba (Pua’ Muriba Kadhi Campalagian XI 1883-1889 M). Dikisahkan, bahwa Pua' Muriba atau Annangguru Kaiyyang mengajak Syekh Abdul Karim agar bersedia datang mengunjungi daerah Campalagian untuk mendakwahkan ajaran Islam terutama membangun pendidikan Agama Islam di sana. Ajakan dan permohonannya dikabulkan akhirnya datang Syekh Abdul Karim di Campalagian (sekitar tahun $1883 \mathrm{M}$ ).

Sejak saat inilah ditengarai sebagai awal perkembangan tradisi Mangangaji kitta. Usaha ini kemudian dilanjutkan oleh Arsyad Maddappungan setelah Abdul Karim kemudian kembali ke Pontianak. Pada masa Maddappungan, pengajian kitab semakin berkembang terlebih setelah kedatangannya Syekh Hasan al-Yamani ke Campalagian.

Maddappungan merupakan murid dan kader unggulan yang melanjutkan perjuangan sang guru sehingga beliau mencetak banyak murid dan kader yang tidak hanya terbatas di Campalagian tapibanyak tersebar di berbagai daerah di Sulawesi Selatan, karena pengajian beliau banyak dihadiri muridmurid yang berasal dari berbagai latar belakang dan daerah di wilayah Sulawesi dan bahkan ada dari luar Sulawesi. Murid Maddappungan inilah kemudian menginiasiasi lahirnya lembaga pendidikan yang bernama Pesantren Calon Alim Ulama. Hanya saja walaupun lembaga ini bernamakan pesantren, 
namun praktek transmisi ilmu masih menggunakan pola pengajaran yang dikembangakan oleh Maddapungan yaitu sorogan (dalam termin lokal Madar dikenal dengan mangngolo). Sementara tempat belajar tersebar di rumah guru-guru yang menjadi tenaga pengajar. Hanya saja materi yang diberikan sudah bervariasi. Misalnya dalam satu kesempatan seorang santri membaca kitab Fathul Qarib di salah seorang tetapi pada waktu yang lain ia juga bisa membaca kitab lain pada guru yang lain.

Tradisi manngngaji kitta' dengan sistem tradisional ini hingga kini menjadi trademark Campalagian. Setiap tahunnya Campalagian didatangi puluhan santri dari luar Campalagian bahkan Polman hanya untuk sekedar belajar membaca kitab. Mereka pada umumnya mantan santri di beberapa pondok pesantren seperti DDI Mangkoso dan Pesantren As'adiyah maupun mahasiswa Perguruan Tinggi Agama Islam di Makassar. Pada umumnya mereka memanfaatkan waktu liburan sekolah seperti bulan Ramadhan atau libur semester.

Problem yang muncul kemudian ketika kuantitas pengajar kitab kuning semakin kurang, dengan semakin banyaknya annangguru yang meninggal dunia, sementara kaderisasi berjalan stagnan. ini disebabkan karena santri lokal yang mangngaji kitta' sangat minim dibandingkan santri dari luar daerah. Belum lagi metode pembelajaran yang dianggap masih sangat klasik dan belum mengakomodir metode modern. Di samping sistem pengajian ini secara umum belum dikelola dengan manajemen modern. Oleh karena itulah, Abd. Latif Busra menginisiasi pendirian Yayasan Assalafi yang membawahi Pesantren Salafiyah Parappe Campalagian. Kurikulum pesantren ini tetap memfokuskan pada pembelajaran kitab kuning dengan menitikberatkan pada penguasaan kaidahkaidah Nahwu-Sharaf. Di samping Pesantren Salafiyah Parappe, kini pengajian kitab kuning secara tradisional di rumah annangguru masih bisa ditemui di Campalagain khusunya di Desa Bonde dan Desa Parappe. Tradisi mangngaji kitta' ini mesti dipertahankan karena sudah terbukti mampu melahirkan qari-qari kutub turats yang handal.

\section{Mangngolo ke Arsyad Maddappungan}

Bekal pelajaran dari beberapa ulama di tanah suci dijadikan modal untuk mengembankan dakwah dan pendidikan Islam di Campalagian. Sistem pendidikan yang diinisiasi oleh Maddapungan adalah sistem pengajaran yang dengan sistem sorogan. Sistem tersebut mengacu pada kitab yang diajarkan. Jika kitab tersebut selesai dikhatamkan, santri dapat melanjutkan ke kitab berikutnya. Sistem ini masih dianut beberapa pesantren tradisional di Nusantara khususnya di Pulau Jawa, seperti Pesantren Lirboyo Kediri Jawa Timur dan Pesantren Sidogiri Pasusruan Jawa Timur. Pesantren yang menganut sistem seperti ini biasanya dikenal dengan pesantren salaf (Misrawi, 2010: 66).

Kitab yang diajarkan meliputi

(Muhammadiyah, 1984: 23):

1. Bahasa Arab, seperti: Saraf Galappo, Matn Ajurumiyah, Syarah Ajurumiyah, Mutamimmah Ajurumiyah, Tashil Nail (syarh Awamil) dan Syarah Ibn 'Aqil.

2. Fikih, seperti: Safinah Al-Najah, Kasyifah alSajah, Fathul Qarib, Fathul Mu'in dan Kifayatul Akhyar.

3. Hadis, seperti: Arbain Nawawi, Tanqihul Qaul, Riyadusalihin, Irsyadul Ibad

4. Tafsir Jalalain dan

5. Irsyad al-Ibad.

Kiprah Maddappungan sendiri dikenal sebagai pelopor tradisi Mangngaji Kitta' di Campalagian. Tradisi ini masih berlangsung hingga kini. Kontinuitas pangngaji kitta' ini tak lepas dari peran Maddappungan dengan mendidik dan melahirkan ulama-ulama lokal yang mumpuni sebagai pembawa tongkat estafet cita-cita Arsyad Maddapungan agar Campalagian menjadi kampung ulama.

Metode pembelajaran yang digunakan yaitu metode mangngolo' yaitu metode dimana tiap santri masing-masing menghadapkan kitab yang dibaca sementara santri yang lain menjadi mustami' (menyimak bacaan santri yang lain). Kelebihan metode ini, yaitu dalam satu waktu para santri bisa mempelajari berbagai materi dari guru. Pembelajaran Kitab Kuning dilaksanakan di rumahnya pada waktu yang ditentukan. Ia kemudian dibantu oleh santri-santri yang sudah dianggap mampu mengajarkan kitab tertentu. Sistem pengajaran yang dikembangkan tidak mengenal sistem klasikal. Lama belajar santri pun tidak tertentu serta tidak mengenal tanda tamat (ijazah). Disiplin belajar pun kurang diperhatikan. Yang terpenting dalam pengajaran ini yaitu kesadaran dan kemauan santri uuntuk menamatkan suatu kitab. Guru yang mengajar juga tidak digaji hanya semata dengan niat lillahi taiala (hanya mengharap pahala dari Allah swt). Tradisi model pengajian seperti ini akhirnya diwarisi turun temurun hingga kini. Hanya saja kelemahan dari metode ini yaitu 
karena tidak dikelola dengan sistem manajamen modern sehingga sistem pendanaan pun seadanya dan tidak memiliki sekretariat atau kantor secara khusus.

Sistem pengajian mangngolo atau sorogan dengan metodologi yang digunakan, walaupun masih tradisional, namun, terbukti mampu menelorkan kader pangngaji kitta' yang mampu memahami kitab-kitab berbahasa Arab, mampu menguasai qaidah-qaidah bahasa Arab dan fasih membaca kitab-kitab kuning. Secara umum, materi yang diajarkan ditekankan pada persoalan fikih berbasis Mazhab Syafi'i. Ini bisa dilihat dari kitab-kitab yang diajarkan antara lain; Safinatun Najah, Kasifah Sajah Syarh Safinah Najah, Fathul Qarib, Fathul Muin, Kifayatul Akhyar dan Syarh Minhaj. Maddappungan tidak ingin membebani masyarakat yang belum mampu menerima dan mencerna perbedaan madzhab. Di samping itu juga pembelajaran dengan satu madzhab sangat mempermudah bagi santri untuk menguasai materi kitab yang diajarkan secara utuh dibandingkan dengan mengajarkan materi khilafiyah namun pembelajarannya tidak tuntas.

Walaupun demikian, bukan berarti Maddappungan menafikan khilafiyah madzhab. Ini bisa dilihat pada praktek niat puasa Ramadhan dimana masyarakat diajarkan untuk berniat menurut versi madzhab Syafi'i yaitu berniat tiap malam di samping itu juga berniat menurut madzhab Maliki dengan berniat cukup malam pertama saja untuk satu bulan (Muhammadiyah, 1984: 33-34).

Tradisi pengajian kitab yang dikembangkan yang yang bercorak Syafi'iah ini dengan menekankan terlebih dahulu penguasaan Nahwu Saraf terbukti ampuh mencetak kader-kader ulama. Kecenderungan pada corak syafi'iah ini karena memang secara umum berlaku di Indonesia bahkan Asia Tenggara. Di samping itu, ia juga berguru pada Said Al Yamani yang merupakan Mufti Syafi'iah di Haramain serta kolaborasinya dengan Syekh Hasan al-Yamani. Ia menjadi penerjamah bagi Syekh Hasan Yamani saat melaksanakan pengajian (Bosra, 2008: 139).

Di samping materi fikih diajarkan juga materi sperti tauhid, tafsir, hadis dan akhlak. Pemilihan materi fikih ini sendiri berbeda dengan kecenderungan pemikiran keagamaan yang berkembang di Mandar secara umum yang cenderung bercorak tasawuf misalnya di Majene telah berkembang tarekat Naqsyabandiyah dan Qadiriyah. Bahkan di Campalagian tepatnya di
Desa Lapeo, Imam Lapeo mengembankan Tarekat Syadziliyyah walaupun akhirnya ia lebih memilih melanjutkannya di Pambusuang. Sehingga dewasa ini, Campalagian lebih terkenal dengan pengajian kitab kuning yang berbasis fikih sementara tasawuf justru kental dengan corak tasawufnya.

Perkembangan berbagai corak pemikiran di Polman menjadi warna tersendiri. Perkembangan pemikiran ini berjalan berdampingan dimana masyarakat memiliki banyak opsi untuk mempelajari pemikiran keagamaan. Misalnya, Muh. Tahir (Imam Lapeo) yang dikenal sebagai pelopor Tarekat Syadziliah di Lapeo dan Pambusuang berguru kepada Syekh Hasan al Yamani yang dikenal sebagai sparing partner bagi Maddappungan yang di Campalagian (Zuhriah, 2013: 25). Begitupula Abdurrahman Qadir sebagai mursyid tarekat Naqsyabandiyah di Majene berguru kepada Syekh Hasan al Yamani. Misalnya juga Najamuddin Thahir anak dari Muh. Thahir berguru kepada Maddappungan hingga menjadi seorang pelopor berdirinya Pesantren Calon Alim Ulama.

Sebelum materi-materi inti diajarkan berupa fikih, tauhid, hadis maupun tafsir, santri harus terlebih dahulu menguasai kaidah-kaidah bahasa Arab berupa nahwu dan saraf yang meliputi Kitab Saraf Galappo, Matan dan Syarh Aljurumiyah, Mutammimah Ajurumiyah dan Syarh Awamil. Kitab Saraf Galappo merupakan kitab saraf kombinasi bahasa Arab dan bahasa Bugis. Kitab ini secara turun-temurun diajarkan di Campalagian, sementara di kampung asalnya yaitu Bugis kitab ini seolah terlupakan.

\section{Arsyad Maddappungan dengan Syekh Hasan Al Yamani}

Pada tahun 1925, Said Al Yamani yang dikenal sebagai Mufti Syafi'iyah di Mekah berkunjung di Campalagian. Pasca peristiwa kudeta terhadap Syarif Husain, Syekh Hasan Al Yamani beserta rombongan menuju Nusantara antara lain Abdullah Basalamah. Eksodus ulama yang belajar dan mengajar di Timur nampaknya terjadi secara besar-besaran seperti Ahmad bone, Muuhammad As'ad (Gurutta Sade), Abubakar, Muhammad Tahir. (Bosra, 2008: 139).

Syekh Hasan Yamani langsung ke Campalagian dimana setahun sebelumnya bapaknya Said Al Yamani berkunjung. Selanjutnya ia berkeliling Sulawesi Selatan dengan mengajarkan ilmunya sehingga melahirkan ulama-ulama besar, misalnya AG. As'ad, AG. Muh. Ramli dan terakhir AG. Muhammad Nur. Di samping itu, ia membantu 
Arsyad Maddapungan mendakwahkan agama Islam. Maddappungan sendiri menjadi penerjemah ketika Syekh Hasan Yamani memberikan pengajian di Masjid Raya Campalagian. Keberadaan kedua ulama ini, memancing para santri dari luar Campalagian untuk belajar kepada keduanya. Hingga pada akhirnya menjadikan Campalagian sebagai kampung ulama dan santri. Kurang lebih 7 tahun di Campalagian, ia kemudian kembali ke tanah suci setelah suasana negara yang dikuasai keluarga Saudi berangsur aman. Walaupun Syekh Hasan Yamani telah ke kampung halamannya, pengajian kitab kuning yang diasuh Maddappungan tetap berjalan dengan dibantu oleh santri-santri sudah dainggap mampu mengajarkan materi kitab yang diajarkan.

Pada Tahun 1955, H. Muhammad Said (pendiri Pesantren Syekh Hasan Yamani) naik ke Tanah Suci untuk menunaikan ibadah Haji. Disana ia bertemu dengan Syekh Hasan Yamani yang kemudian berpesan agar mendirikan sebuah lembaga pendidikan yang kelak dikenal Pesantren Syekh Hasan Yamani.

Sebelum kedatangan Syekh Hasan Yamani di Campalagian, seorang Ulama dari Yaman yaitu Said Alwi bin Hasan Jamulullail juga datang di Campalagian. Ia juga kemudian membantu Qadhi Abdul Hamid dan Maddappungan mengadakan pengajian di Campalagian sampai ia wafat dan dimakamkan di area Masjid Besar Campalagian. Sebelum ke Campalagian, Said Alwy terlebih dahulu singgah di Manjopai dan Pambusuang. Konon sewaktu ia wafat, ketiga daerah tersebut berebut agar Said Alwy dimakamkam di daerahnya walaupun pada akhirnya diputuskan bahwa ia dimakamkam di Campalagian (Ismail, 2012: 69).

Riwayat hidup Maddappungan tersebut menggambarkan bahwa ia adalah seorang ulama besar. Jika Muh. As'ad (Gurutta Sade') disebut sebagai aktor pembentuk jaringan pesantren dan ulama di Sulawesi Selatan (Arif, 2007: 190), maka Maddappungan juga bisa disebut aktor pembentuk jaringan ulama di wilayah Mandar. Ini bisa dilihat dari kader santri yang ditelorkan. Santri-santri tersebar ke beberapa daerah dan selanjutnya meneruskan cita-cita perjuangan sang guru dengan mengembankan tradisi mangngaji kitta'. Ulama yang belajar ke Maddappungan antara lain: As'ad/Daeng (Majene), Sayyid Abu Bakar (Baturoro), Abdul Kadir (Batuputih/Dosen Unizal Ujung Pandang), Burhan (Mangkoso), Baharuddin (Pambusuang), Abd. Halim (Maselembu), Mukhtar Badawi
(Polewali/Ketua MUI Polmas), Buchari (Polewali), Najamuddin Tahir (Lapeo Campalagian), Muh. Zain (Menantu/Qadhi Campalagian), Mahmud Ismail (Imam Pappang Campalagian) dan lain sebagainya (Muhammadiyah, 1984:58-59).

Melihat jaringan murid dan dan gurugurunya, Maddappungan merupakan ulama besar yang berpengaruh di wilayah Mandar khusunya Campalagian. Perannya sebagai pelopor pengajian kitab kuning membuat ia digelari "Puang Panrita". Kini makamnya setiap hari jumat ramai diziarahi oleh para pangngaji kitta'. Tentu saja dengan harapan berkah dari Allah swt, serta iringan doa semoga Allah swt menerima amal salehnya.

\section{PENUTUP}

Maddappungan merupakan seorang ulama kharismatik di Campalagian yang dikenal dengan panggilan Puang Panrita. Ia merupakan Ulama kelahiran Belokka Sidrap.

Sebagai ulama yang memiliki ilmu yang mendalam, maddappungan dipercaya sebagai Qadhi di Sidenreng, Binuang dan Campalagian. Di samping itu, ia juga mengembangkan tradisi mangngaji kitta' di Camapalagian hingga ia mampu melahirkan beberapa ulama lokal yang melanjutkan tradisi mangngaji kitta' tersebut. Hingga kini tradisi itu masih bertahan di Campalagian termasuk di rumah Maddappungan yang dilanjutkan oleh Hudaedah (Annanguru Edda).

\section{UCAPAN TERIMA KASIH}

Ucapan terima kasih kepada seluruh pihak yang turut membantu terlaksananya penelitian ini mulai dari awal sampai akhir. Ucapan terima kasih terkhusus buat seluruh Annangguru di Campalagian, dengan keikhlasannya mengembangkan tradisi mangngaji kitta' sehingga penulis bisa belajar membaca kitab kuning sekaligus memudahkan peneliti dalam pelaksanaan penelitian ini.

\section{DAFTAR PUSTAKA}

Arif, Syamsudin. 2007. Aktor Pembentuk Jaringan Pesantren di Sulawesi Selatan 1928-1952. 10/2. Lentera Pendidikan.

As'ad. et’al. 2012. Buah Pena Sang Ulama. Jakarta: Orbit.

Azra, Azyumardi. 2009. Tarajim Ulama Nusantara: Ke Arah Sejarah Sosial-Intelektual Ulama Kita, "Pengantar" dalam Bibit Suprapto, Ensiklopedi Ulama Nusantara: Riwayat 
Hidup, Karya, dan Sejarah Perjuangan 157 Ulama Nusantara. Jakarta: Gelegar Media Indonesia.

Bibit Suprapto, 2009. Ensiklopedi Ulama Nusantara: Riwayat Hidup, Karya, dan Sejarah Perjuangan 157 Ulama Nusantara. Jakarta: Gelegar Media Indonesia.

Bosra, Mustari. 2008. Tuang Guru, Anrong Guru dan Daeng Guru: Gerakan Islam di Sulawesi Selatan. Makassar: La Galigo Press.

Burhanuddin, Jajat. 2012. Ulama dan Kekuasaan: Pergumulan Elit Muslim Dalam Sejarah Indonesia. Jakarta: Mizan.

Ismail, Arifuddin. 2012. Agama Nelayan: Pergumulan Islam dengan Budaya Lokal. Yogyakarta: Pustaka Pelajar.

Kadir, Abd. 2007. Ajaran Keselamatan Versi Sumardin dalam Varian Gerakan Keagamaan. Makassar: Indobis.

Misrawi, Zuhairi. 2010. Hadratussyaikh Hasyim Asy'ari: Moderasi, Keumatan dan Kebangsaan. Jakarta: Kompas Media Nusantara.
Muhammadiyah, M. Urwah. 1984. Kiyai Haji Arsyad Maddeppungeng: Suatu Study Tentang Pengaruh Ulama Dalam Masyarakat Kabupaten Polmas Skripsi Sarjana, Fakultas Adab IAIN Alauddin, Ujung Pandang.

Musaddad, Aco. 2008. Annangguru Dalam perubahan Sosial di Polewali Mandar. Makassar: La Galigo Press.

Muslim, Abu. 2012. Ulama Perempuan di Bonde Polewali Mandar: Study Biografi Annangguru Hudaedah. Makalah disampaikan pada seminar tahap II tahun 2012 Balai Litbang Agama Makassar.

Pawiloy, Sarita. et. al. 1981 Sejarah Pendidikan Daerah Sulawesi Selatan. Ujung Pandang: Departemen Pendidikan dan Kebudayaan Proyek Inventarisasi dan Dokumentasi Kebudayaan Daerah.

Zuhriah. 2013. Jejak Wali Nusantara: Kisah Kewalian Imam Lapeo di Masyarakat Mandar. Yogyakarta: Pustaka Ilmu. 